CRISE DO CAPITAL E ORÇAMENTO PÚBLICO DA HABITAÇÃO SOCIAL NO BRASIL

\author{
Aline Cavalcanti de Abreu \\ Universidade do Estado do Rio de Janeiro (UERJ)
}

\title{
CRISE DO CAPITAL E ORÇAMENTO PÚBLICO DA HABITAÇÃO SOCIAL NO BRASIL
}

Resumo: O presente estudo trata do financiamento da habitação social no Brasil no período de 2006 a 2012. Para isso, a metodologia envolveu a pesquisa teórica e do orçamento público da União. A institucionalização da política habitacional se desenvolveu num contexto de tomada do Estado como indutor de uma macroeconomia sob o ideário do social-liberalismo. Nessa perspectiva, ocorreu a reestruturação do mercado imobiliário e sob a crise econômica de 2008 a implementação de medidas anticíclicas para minimizá-la. Para a promoção da habitação social tivemos o Fundo Nacional de Habitação de Interesse Social orientado a satisfazer as necessidades habitacionais da população. Contudo, este foi paulatinamente desfinanciado e esvaziado de seu sentido político. Em 2009, foi criado o Programa Minha Casa Minha Vida com caráter de privilegiamento do produtor privado, o que possibilita a punção de fundo público e a redução da responsabilidade do Estado sob a habitação social como direito social.

Palavras-chave: Crise do capital, Política de habitação social, Orçamento público.

\section{CAPITAL CRISIS AND PUBLIC SOCIAL HOUSING BUDGET IN BRAZIL}

Abstract: This study deals the financing of social housing in Brazil between the years 2006 to 2012. For this purpose, the methodology involved the theoretical research and the Union's public budget. The institutionalization of the housing policy developed in a context of state taken as inducer of macroeconomics under the social liberalism of ideas. From this perspective, it occurred the restructure of the housing market and under the economic crisis of 2008 measures were implemented to minimize it. For the promotion of social housing we had the National Funding for housing of social interesting oriented to meet the housing needs of the population. However, this was gradually non-funding and withdraw from its political sense. In 2009, it was created the Programa Minha Casa Minha Vida with character of the private producer privileging to continue taking in the public fund and the State's to reduce under the politic of social housing as a social right.

Key words: Capital Crisis, Social housing policy, Public budget. 


\section{INTRODUÇÃO}

Desde 2004, a reestruturação do mercado imobiliário, com suporte financeiro, institucional e político do Estado, vem trazendo importantes ganhos para a acumulação capitalista do setor. No âmbito da política social, se institucionalizam os programas financiados pelos recursos do Fundo Nacional de Habitação de Interesse Social (FNHIS), objeto de intensa mobilização das organizações populares urbanas e marco da retomada da responsabilidade do Estado na promoção de habitação social no país. Em contraposição, a crise econômica de 2008 e os ideais do socialliberalismo elegeram 0 espaço como instrumento anticíclico de retomada das taxas de lucro por meio do maior programa habitacional, desde o fim do Banco Nacional de Habitação (BNH) em 1986, o Programa Minha Casa Minha Vida (PMCMV). Nesse contexto, 0 trabalho pretende analisar a política de habitação social brasileira a partir desses programas de habitação social tendo no orçamento público 0 instrumento para análise dos caminhos tomados por essa política social.

A metodologia aplicada versa sobre a pesquisa bibliográfica e documental que instituem o Sistema Nacional de Habitação de Interesse Social (SNHIS) e o PMCMV. Já os dados orçamentários trabalhados terão por base de pesquisa as fontes de informação do Siga Brasil e os dados da Lei Orçamentária Anual
(LOA) e suas execuções durante o período de 2006 a 2012 (BRASIL, 2012).

Para o desenvolvimento do estudo, dividimos o texto em duas seções, a primeira analisa o processo de centralização de capitais movida pela reestruturação do mercado imobiliário e seu atrelamento às novas exigências para o desenvolvimento do capital no Brasil. Tal fato ganha dimensões particulares após a crise de 2008, a que exigiu medidas anticíclicas do Estado na intervenção em infraestrutura física e social com vista a permanecer privilegiando o produtor privado. A segunda se debruça sobre a questão tributária da propriedade da terra e o financiamento da habitação social no Brasil a partir do FNHIS e do PMCMV, considerando seus pontos críticos.

\section{A REESTRUTURAÇÃO DO MERCADO IMOBILIÁRIO BRASILEIRO: centralização} de capitais e a pulsão de fundo público

$$
\text { A reestruturação do mercado }
$$
imobiliário brasileiro está envolvida num processo global do capitalismo monopolista que possui como característica a concentração e a centralização de capitais (PAULO NETTO, 2009). O movimento de concentração e centralização é mobilizado pela busca capitalista pelo superlucro e pela produção de mais-valia. A competitividade e a disputa para acumulação $e$ monopólio pelas frações de capitalistas marcam o desenvolvimento geográfico desigual. 
Para o desenvolvimento capitalista, o Estado possui papel central na criação das condições gerais de produção. Segundo Mandel (1982, p. 333), as principais funções do Estado são "[...] criar condições gerais de produção que não podem ser criadas pelas atividades particulares da classe dominante."; conter as ameaças que questionam o modo de produção capitalista por meio do uso da força legalinstitucional repressiva; e contribuir para a criação de estratégias de integrar e manter a classe trabalhadora dentro da lógica capitalista, aceitando as ideologias dominantes (função de hegemonia).

Num ambiente de crise, no sentido de minimizar seus efeitos, o Estado põe em marcha medidas anticíclicas que envolvem 0 estabelecimento de políticas que proporcionam garantias econômicas aos processos de valorização e acumulação (MANDEL, 1982) e que garantam a estratégia de ofensiva ideológica sobre os trabalhadores, no sentido de criar um ambiente de legitimidade para as iniciativas tomadas. As medidas anticíclicas no urbano são respostas do Estado à crise do capital, mas também produção do espaço ${ }^{1}$. 0 Estado, ao definir medida anticíclica sobre 0 urbano, como "[...] agente facilitador dos fluxos de capital para a produção do ambiente construído. " (COSTA, 2003, p. 10), expressa também sua dimensão política, seu caráter de classe, pondo em movimento suas funções na criação das condições gerais de produção capitalista.
Os padrões de desenvolvimento capitalista sobre o Brasil marcaram, na década de 90, a adoção de uma política macroeconômica de viés neoliberal, orientada por

$$
\begin{aligned}
& \text { [...] reformas e ajustes, } \\
& \text { (que) possibilitaram } \\
& \text { incentivos de liberalização } \\
& \text { e desregulamentação } \\
& \text { comercial e privatizações } \\
& \text { para assegurar a } \\
& \text { competitividade e manter } \\
& \text { a credibilidade externa e } \\
& \text { interna. (IAMAMOTO, } \\
& \text { 2008, p. 108-114). }
\end{aligned}
$$

Para Filgueiras e Gonçalves (2007) a política macroeconômica do governo Lula possuía o caráter de continuidade ao modelo liberal periférico conduzido no governo de Fernando Henrique Cardoso (FHC), permanecendo as taxas de desigualdades sociais, reduzido crescimento econômico, inserção passiva na mundialização do capital e grande vulnerabilidade externa estrutural. Assim, o processo foi apontado por Behring (2012) como uma contrarreforma do Estado, possuindo reflexo na restrição de investimentos em políticas sociais e na focalização dos programas, na escalada do desemprego e na flexibilização/precarização dos contratos de trabalho.

Com a falência do ideário neoliberal exposto no Consenso de Washington e na perspectiva de garantir legitimidade ao projeto de desenvolvimento capitalista aos países periféricos, a ideologia dominante passa a apregoar o crescimento econômico com 
equidade social. Entra na cena política, o debate do novo-desenvolvimentismo com traço fortemente ideológico de um suposto desenvolvimento econômico com distribuição de renda. Na análise de Mota, Amaral e Peruzzo (2012) o que está em jogo é a promoção de um processo de repolitização regressiva da política, pois sob a defesa de uma economia nacional, se alicerça políticas sociais compensatórias, consentimento de classe e o fortalecimento da inserção passiva do país no mercado mundial.

$$
\text { É sob as condições do social- }
$$
liberalismo ${ }^{2}$ que se articula 0 processo de centralização de capitais atrelado ao mercado financeiro que vem fortalecendo o mercado imobiliário brasileiro. Por setor imobiliário partilhamos da definição de Botelho (2007, p. 25) que o coloca como um

[...] conjunto de atividades que envolvem os subsetores de materiais de construção, de construção de edifícios e obras de engenharia civil, bem como aqueles ligados ao terciário, tal como atividades imobiliárias e prediais.

No âmbito da construção civil, o subsetor que trata da produção habitacional (entre outras) é o de Construção de Edifícios e Obras de Engenharia civil.

Para garantir seu fortalecimento, 0 capital imobiliário busca no espaço a valorização de capital e a realização da maisvalia apropriada da força de trabalho. 0 mercado imobiliário promove as empresas da construção civil na definição de todo o ciclo produtivo, envolvendo a

[...] incorporação, a
construção e a
comercialização de
unidades habitacionais,
abrangendo funções
anteriormente atribuídas a
diversos agentes da
promoção imobiliária
(proprietário de terras,
incorporador, construtor e
vendedor). (SHIMBO,
2011, p. 153).

O Estado, ao investir em infraestrutura física e social com vista a promover o crescimento econômico, estimula 0 mercado imobiliário e reafirma seu compromisso com a perspectiva social-liberal. Para Cardoso e Aragão (2011), foi a partir de 2004 que se inicia a reestruturação do mercado imobiliário, entendido pela entrada deste no mercado financeiro, oferta de ações em Bolsa de Valores, captura de recursos via mercado de capitais articulado a pulsão de fundo público. A reestruturação do setor também

[...] proporcionou [...] a
aquisição de outras
empresas menores,
localizadas em outros
estados ou
especializadas em nichos
de mercado. (SHIMBO,
2011, p. 45).

A diversificação construtiva e de mercado, além dos estímulos do Estado no que tange a revisão da carga tributária, segurança jurídica e diversificação de acesso a recursos públicos. 
Dentre as empresas com maior rede de poder e capital acumulado do país estão a Construtora Norberto Odebrecht, Construtora Andrade Gutierrez S/A e Cyrela $S / A$, as envolvidas na reestruturação do mercado imobiliário estão a Camargo Correia, OAS, Queiroz Galvão e Carvalho Hosken. Essas se destacam entre as maiores empresas de capital aberto, por atuarem no setor da construção civil, de participarem em consórcios e parcerias público-privadas em grandes empreendimentos de infraestrutura física e social, por contarem com financiamento de bancos públicos como Caixa Econômica Federal (CEF) e Banco Nacional do Desenvolvimento Econômico e Social (BNDES) e por comporem a cadeia produtiva de instituições estrangeiras, realizam emissão de remessas a suas matrizes.

Tal realidade reafirma as proposições de Harvey (2005) que sinaliza que está em curso uma estratégia de mudança da governança das cidades, a qual denomina como empreendedorismo urbano. Tal estratégia envolve a ênfase na parceria público-privada por meio de uma associação entre classes dominantes locais e governos locais, com o objetivo de atrair investimentos externos - exemplos são os projetos de revitalização de área centrais, grandes obras de infraestrutura e remoções de trabalhadores de áreas valorizadas; além da absorção, pelo poder público, dos riscos das iniciativas empreendedoras.
Mesmo diante das diversas estratégias para garantir a taxa de acumulação capitalista, as crises são recorrentes e estruturais ao sistema. A mais recente, que atingiu o mundo em 2008/2009, provocou um efeito cascata, atingindo países da União Europeia, da Ásia e da América Latina. Mas pelo caráter do desenvolvimento geográfico desigual do capital, esses efeitos foram diferenciados entre os países, a depender do grau de influência do crédito na economia de cada um. $O$ espaço e a urbanização tornam-se mercadorias no capitalismo, por seu potencial de absorção de excedente de capital e de trabalho e por elas dependerem da presença do crédito e do endividamento para dinamizar 0 processo de desenvolvimento urbano. Tais mercadorias também criam as condições para o surgimento de crises, cujo impacto nos países periféricos significou o aumento da desigualdade social e da concentração de riqueza - como a valorização imobiliária das favelas cariocas e os despejos de comunidades em áreas com potencial especulativo - e o aprofundamento da mercantilização da moradia e das demais políticas urbanas. $\mathrm{Na}$ análise de Harvey (2011), a resposta à crise tomada pela classe dominante e do Estado será a continuidade da centralização de capital e de seu poder de classe.

No Brasil, as medidas anticíclicas adotadas pelo governo foram investir no setor de construção civil, mantendo iniciativas na área de infraestrutura e a expansão do crédito pelos bancos públicos para o setor. Tais 
medidas foram justificadas pelo efeito multiplicador da construção civil sobre a economia, movimentando setores de insumos e equipamentos, emprego de mão de obra de baixa qualificação, manutenção da renda e estimulo ao consumo. Alguns dos reflexos das medidas anticíclicas foram que o desempenho do setor da construção na economia do país correspondeu a 5,7\% do Produto Interno Bruto (PIB) em 2012 (DEPARTAMENTO INTERSINDICAL DE ESTATÍSTICAS E ESTUDOS SOCIOECONÔMICOS, 2013), impulsionado por investimentos na cadeia produtiva em torno de $\mathrm{R} \$ 349$ bilhões. Em, 2010, o PIB da Construção representou 11,6\% de crescimento, o maior em 24 anos e superior ao crescimento percentual do PIB do país. Contudo, se ao setor da construção civil foi atribuído o dito efeito multiplicador, este se estende às suas mazelas, como a elevação do preço da terra e dos imóveis, periferização dos empreendimentos de habitação social, mercado de trabalho com baixos salários e precários direitos trabalhistas, aumento do preço dos insumos que repercute sobre a autoprodução das moradias.

Segundo Cardoso e Aragão (2011), a partir de 2009, as mudanças para conter a crise provocaram uma clara indução da política habitacional ao crescimento econômico. Parcela considerável dos empreendimentos habitacionais destinados aos trabalhadores das classes populares foi construída nas periferias das cidades, dotada de baixa infraestrutura social e mobilidade urbana. Esses empreendimentos garantiram 0 lucro das empresas, mas requereram recursos do fundo público na expansão dos equipamentos e serviços sociais. A produção de habitação social pelo mercado acompanha a dinâmica territorial e econômica em que 0 empreendimento se localiza, envolvendo as possibilidades de lucro para o produtor, isto é, a busca por terras mais baratas envolve a disputa pela apropriação, por parte do capitalista produtivo, do maior montante de mais-valia que iria para o capitalista fundiário. Assim, as necessidades habitacionais não coincidem com as perspectivas do mercado.

\section{FINANCIAMENTO DA HABITAÇÃO}

SOCIAL: o Fundo Nacional de Habitação de Interesse Social e o Programa Minha Casa Minha Vida

A história do acesso à moradia por segmentos da classe trabalhadora no Brasil, sempre esteve relacionada à autoprodução, à mercantilização e à ocupação ilegal do solo, sendo poucas as iniciativas no âmbito da promoção pública com efeito contínuo e de relativa cobertura para atender demandas por habitação social adequada. Maricato (2001) destaca que a falta de alternativa habitacional impôs a forma de estar na cidade por segmentos dos trabalhadores e alerta que enquanto esta for a alternativa para a maior parte da população, o Estado e o mercado não alterarão suas formas de intervenção, orientada 
para a especulação, a mercantilização e a política habitacional focalizada e fragmentada.

Então pensamos: qual é a alternativa possível ante a real concentração de propriedade fundiária no país? Qual a estrutura tributária da terra e até que ponto ela possibilita financiar a habitação (e a política urbana) no Brasil? A priori, identificamos que os recursos das políticas urbanas não são vinculados aos tributos sobre o patrimônio, como o Imposto sobre Propriedade Territorial Urbana (IPTU), 0 Imposto sobre Transmissão de Bens Imóveis (ITBI) e o Imposto Sobre Propriedade Territorial Rural (ITR). Isso porque esses são impostos que compõem o orçamento de municípios e da União, mas que não exigem contrapartida ao contribuinte. Para se garantir um fluxo contínuo de recursos para a política urbana, seria necessário a instituição de algum tipo de instrumento orçamentário como percentual mínimo ${ }^{3}$ de aplicação do orçamento público ou contribuição social vinculada.

A questão fundiária, pedra angular de todos os projetos habitacionais implantados no país até agora, permanece concentrada e pouco tributada, beneficiando os grandes proprietários fundiários urbanos. Afonso e Castro (2013) assinalam que a participação do patrimônio imobiliário na carga tributaria brasileira foi de $1,06 \%$ do PIB em 2012. Já 0 poder de arrecadação do IPTU correspondeu, em média, a apenas 5,3\% da receita dos municípios no mesmo período. Os tributos como IPTU, ITBI e ITR podem ser considerados regressivos, pois possuem baixa arrecadação e maior incidência sobre as pequenas propriedades. Assim posto, o padrão de concentração fundiária aprofunda a segregação socioespacial no Brasil, o que dificulta o acesso à terra urbanizada como forma necessária à reprodução da força de trabalho, restando moradias periféricas, precárias, adensadas e de alto custo aos trabalhadores.

Além da baixa tributação fundiária, o financiamento habitacional também é acompanhado por desonerações fiscais. Essas desonerações atingem o setor da construção civil. Dados apontam que os gastos tributários em relação ao PIB corresponderam a 3,10\% no período de 2006 a 2012, representando cerca de $R \$ 146$ bilhões apenas em 2012. Os gastos tributários relacionados à habitação obtiveram uma média de $5 \%$ em relação ao montante total das desonerações, atingindo $\mathrm{R} \$ 40$ bilhões nos anos estudados.

Dessa forma, sem a contribuição de fontes de recursos vindas da taxação sobre o patrimônio fundiário, temos desde a criação do $\mathrm{BNH}$, em 1966, um modelo de financiamento habitacional que possui, como pilar, dois instrumentos, que são os recursos do Fundo de Garantia do Tempo de Serviço (FGTS) e do Sistema Brasileiro de Poupança e Empréstimos (SBPE), ambos regulados pelo Sistema Financeiro de Habitação (SFH) (CARDOSO; ARAGÃO, 2013). O SFH conforma um 
[...] modelo, que continua em vigor, de criação de instrumentos de captação de poupanças privadas (voluntárias ou compulsórias), remuneradas a baixas taxas de juro e garantidas pelo governo federal contra a inflação e contra a possível falência dos agentes financeiros. (CARDOSO; ARAGÃO, 2013, p. 18).

Esses dois instrumentos de captação (FGTS e SBPE) mobilizaram cerca de $\mathrm{R} \$ 569$ bilhões e financiaram 5.432 .000 unidades habitacionais no período de 2006 a 2012. Há também outras fontes como as emendas parlamentares e os fundos contábeis compostos via orçamento público, mas com menor peso de alocação de recursos para esta política.

O Estado possui o poder legal sobre a tributação. As tributações são fonte de recursos do fundo público que representa 0 mecanismo do Estado para reter recursos que garantam a produção e a reprodução do capital e da força de trabalho. De outro modo, o fundo público advém

[...] da extração de recursos da sociedade na forma de impostos, contribuições e taxas, da mais-valia socialmente produzida [...], e de parte do trabalho excedente que se transformou em lucro, juro e renda da terra, sendo apropriado pelo Estado. (SALVADOR; TEIXEIRA, 2012, p. 126).
Isto é, o fundo público é formado por parte do trabalho necessário e do trabalho excedente que é apropriado pelo Estado para desempenhar suas funções.

O orçamento público é uma das expressões do fundo público e é composto por instrumentos de planejamento das finanças públicas no âmbito das receitas e despesas alocadas pelo Estado. Entre os instrumentos está o Plano Plurianual (PPA), definido como um plano de governo, contendo estratégias e diretrizes gerais a serem executadas nos 4 anos. Para esse trabalho, analisamos os PPA's 2004-2007, 2008-2011 e 2012-2015 por envolverem os anos de pesquisa do escopo deste trabalho (2006 a 2012) e por exporem as orientações gerais dos governos sob a gestão do Partido dos Trabalhadores (PT).

Um estudo identificou que nos Planos Plurianuais dos últimos 10 anos a atual política econômica se alicerçava sobre o tripé superávit primário, câmbio flutuante e metas inflacionárias (BEHRING et al., 2013). Contudo, diante da crise econômica de 2008, o Estado brasileiro utilizou 0 fundo público para impulsionar os investimentos na economia, voltados ao incentivo do consumo de massa e 0 estímulo ao crédito. Medidas no âmbito da provisão de infraestrutura física e social, como 0 PMCMV, também fizeram parte dos investimentos. Mesmo acionando medidas anticíclicas para estimular os investimentos e 0 consumo, a economia, desde então, não tem 
tido o êxito em ternos de crescimento, com taxas abaixo dos demais países emergentes.

Para a política habitacional, os dados dos Planos Plurianuais demonstraram que a meta de recursos para habitação era de $\mathrm{R} \$ 486$ bilhões, isto é, uma média de $5 \%$ do montante total destinado aos programas finalísticos 4 ou área temática. Contudo, a habitação vem sendo fragmentada dentro do planejamento governamental; primeiro, descolada da área social; e depois dentro da área de infraestrutura fragmentada das demais políticas urbanas, reafirmando a moradia como instrumento anticíclico de política econômica e objeto de pouco interesse político para assegurar a intersetorialidade nas políticas urbanas.

Se no âmbito do planejamento orçamentário do governo a política habitacional ganhava contornos voltados ao crescimento econômico, no âmbito institucional, desde 2003, se estruturava o Ministério das Cidades. Instituído como órgão gestor, o Ministério das Cidades (MCidades) deveria centralizar programas e recursos para o desenvolvimento urbano. Esse é um dado importante, visto que após a extinção do BNH (1986), houve diversas mudanças institucionais, demonstrando 0 quadro de instabilidade política, a fragmentação de ações e a redução da capacidade de financiamento do Estado no trato da habitação.

No MCidades, a estrutura de financiamento habitacional seria composta pelo Sistema Nacional de Mercado, que é destinado à produção habitacional para as camadas de renda média, financiada com recursos do FGTS e SBPE. Já o SNHIS seria destinado à promoção pública de moradia, financiado com recursos do orçamento público e outras fontes não onerosas.

Desenhava-se a institucionalização de um sistema ${ }^{5}$ de moradia popular organizado em nível nacional e disposto a criar alternativas habitacionais, distintas daquelas hegemônicas no país. Ao tratar a moradia 6 como direito e que seu acesso deve ser objeto de intervenção pública, a proposta demonstra que é possível a promoção pública habitacional adequada à classe trabalhadora, cumprindo a função social da propriedade e voltada aos interesses da coletividade, iniciativa essencial num ambiente de contrarreformas e crise do capital.

Para enfrentar a precariedade que cercava a política habitacional como a fragmentação, a baixa cobertura e os parcos recursos, um projeto de iniciativa popular propôs a criação do SNHIS, instituído por meio da Lei $n^{0}$ 11.124, de 16 de junho de 2005. O SNHIS está organizado por plano, o Plano Nacional de Habitação (PlanHab); fundo, o FNHIS; um conselho, o Conselho Gestor do Fundo Nacional de Habitação de Interesse Social (CGFNHIS); e órgão gestor, o MCidades. O SNHIS traz um elemento inovador para o contexto da política habitacional, a centralização administrativofinanceira para os programas na área. Junto com a defesa da moradia como direito humano, a função social da propriedade da terra e 0 
controle democrático, o SNHIS instaura novas possibilidades para a habitação social no país e traz para a responsabilidade do Estado a promoção de moradia para os segmentos pauperizados da classe trabalhadora. $\mathrm{Na}$ promoção habitacional pública, o Estado é 0 promotor e idealizador do projeto, considerando as diretrizes e os princípios da intersetorialidade, do controle democrático e do planejamento urbano regional, direcionado pelo déficit habitacional.

\section{O financiamento do SNHIS foi} regulamentado, em 2006, pelo Decreto $n^{0} 5.796$, de 6 de junho de 2006, que dispôs sobre 0 FNHIS. O FNHIS é o mecanismo de centralização e gerenciamento de recursos para a execução de programas de habitação social no âmbito do SNHIS. Os recursos alocados no fundo são aplicados de maneira descentralizada e os contratos firmados no âmbito do FNHIS devem conter contrapartidas entre os entes federativos. Pautado pela co-responsabilidade e articulação institucional, os municípios e estados que queiram se integrar ao Sistema, devem assinar um termo de adesão e cumprir um conjunto de medidas, como a implementação de planos locais; de conselhos gestores e de fundos. A assinatura do termo de adesão é condição para o repasse de recursos ao Fundo e a possibilidade de realização de consórcios.

Para o financiamento do SNHIS, os recursos viriam, basicamente, do FNHIS, do Fundo de Amparo ao Trabalhador (FAT) e do FGTS, a depender da deliberação dos seus respectivos conselhos gestores. Os recursos para a política habitacional encontram-se no âmbito do orçamento fiscal e o FNHIS, em seu decreto de regulamentação, não possuiu vinculação com nenhuma contribuição social ou percentual mínimo do orçamento geral. Por ser um fundo de natureza contábil ${ }^{7}$ (BRASIL, 2006, art. 7), está sujeito às oscilações de alocações orçamentárias e à disputa de recursos com outras políticas no âmbito do orçamento público. A gestão da operação físico-financeira do FNHIS é de responsabilidade da CEF, que atuando como instituição depositária dos recursos, controla e presta contas da execução dos recursos.

Considerando a moradia adequada na perspectiva dos direitos humanos, Rolnik (2012) aponta que é necessário criar alternativas de acesso à moradia, para além do financiamento, com vista à propriedade privada da terra, e que o Estado possui papel fundamental na oferta de habitação para os segmentos populares. Há que garantir o controle democrático sobre os programas habitacionais e 0 atendimento das demandas de segmentos específicos da população. Nessa perspectiva, os programas operados com recursos do FNHIS atuam sobre demandas de política urbana, não apenas habitacional, contemplando projetos de urbanização de assentamentos precários e a produção habitacional a fundo perdido. Assim, 0 financiamento abarca o acesso a moradia, mas também outros aspectos, como localização, 
acesso a infraestrutura e segurança da posse (ROLNIK, 2012).

No que tange à análise a respeito do financiamento habitacional, identificamos nos dados orçamentários que a função habitação8 vinha obtendo, em média, $0,07 \%$ de recursos alocados no orçamento geral da União. Contudo, com seus recursos em queda, devido a mudança de inserção da política habitacional na economia, a função habitação fechou o ano de 2012 com um percentual de 0,007\% do orçamento geral. Os recursos liquidados na função habitação corresponderam a $R$ \$ 6,6 bilhões, entre 2006 e 2012. Somente no período do Plano Plurianual de 2008-2011, para a função habitação, foi previsto $R \$ 76$ bilhões, porém foram alocados apenas $\mathrm{R} \$ 3,7$ bilhões deste recurso, o que demonstra a discrepância entre a meta exposta no PPA e o montante realmente alocado na função.

No âmbito institucional, 0 MCidades, como órgão gestor, obtinha, em média, até 2011 cerca de 1\% ( $\mathrm{R} \$ 14$ bilhões) do orçamento geral. Contudo, em 2012, houve uma queda na alocação para $0,2 \%$ do orçamento geral, isto é, $21 \%$ ( $R \$ 5,2$ bilhões) dos recursos previstos para o órgão. Devemos considerar que o Ministério das Cidades é responsável pela gestão de diversas políticas urbanas, entre elas a de saneamento e mobilidade urbana.

Quanto ao FNHIS, a participação de seus recursos no interior do MCidades é de grande queda. Entre os anos de 2006 e 2012, os recursos liquidados pelo FNHIS foram de $\mathrm{R} \$$
5,6 bilhões, tendo em 2012 a menor alocação, cerca de $\mathrm{R} \$ 151$ milhões (2,8\% do orçamento total do MCidades). Além dos parcos recursos, temos também a perda de recursos liquidados em relação à dotação inicial, que em 2009 foi de $81 \%$ (o maior percentual liquidado) e em 2012, foi apenas 14\% (o menor percentual). Os programas de urbanização de assentamentos precários e de produção habitacional a fundo perdido, desenvolvidos pelo FNHIS sofreram com a baixa de recursos. No período de 2006 a 2012 esses obtiveram, respectivamente, $\mathrm{R} \$ 3,1$ bilhões e R\$ 1,6 bilhões de alocação de recursos. A pouca influência dos recursos via FNHIS para tais projetos, se contrapõe à prevalência dos repasses oriundos do FGTS, que para a produção de moradia popular destinou $\mathrm{R} \$ 57$ bilhões no mesmo período, por exemplo.

Os dados orçamentários apresentados demonstram que o planejamento e execução da política habitacional, particularmente, de habitação social, não estão sendo desenvolvidos a partir de princípios que envolvem o SNHIS. O desfinanciamento e a fragmentação das ações para outros órgãos desconsideram o controle democrático e 0 planejamento via Plano de Habitação, onde 0 Estado é o promotor da política. O SNHIS constituiu-se como avanço na garantia do direito à cidade à classe trabalhadora, mas enfrenta muitos limites para sua concretização.

Em paralelo à institucionalização do SNHIS, se desenvolvia uma proposta de 
política habitacional atrelada a atender as exigências econômicas. A mundialização do capital fez que a crise econômica de 2008 atingisse vários países, cabendo ao Estado a estratégia de contê-la. Nesse ambiente, 0 mercado imobiliário situado no Brasil, mas globalizado pelas finanças, é protagonista no aumento do preço da terra e da especulação, acompanhado de despejos e remoções em várias cidades brasileiras, particularmente naquelas situadas no eixo dos megaeventos esportivos e megaempreendimentos. Bastos (2012) situa o Brasil no fluxo de capital em busca de oportunidades de remuneração dos investimentos e de novos mercados, tomando a urbanização e a produção habitacional 0 impulso para o desenvolvimento (desigual) capitalista.

A resposta à crise veio na forma do novo-desenvolvimentismo (ou social-liberalismo, sendo mais apropriado), tendo o Estado como indutor da política econômica e articulador do apelo ideológico com vista ao crescimento. Neste contexto é lançado o PMCMV. Segundo Andrade (2011), o PMCMV possui clara associação do setor da construção e do Estado que, sob os efeitos da crise econômica e do período eleitoral, precisava de medidas eficazes para garantir a estabilidade econômica e certa legitimidade política. Entre os argumentos de combate à expressão da questão social urbana, como o déficit habitacional, e do incentivo à construção civil por seu potencial para a criação de postos de trabalho, o fundo público foi destinado a beneficiar a burguesia do ramo da construção. Dessa forma,

[...] as empresas da construção civil, seriam as grandes promotoras e executoras do programa e contariam com incentivos concedidos pelo poder público, ao mesmo tempo em que estariam libertas de uma gestão participativa [como no SNHIS]. (ANDRADE, 2011, p. 43).

O governo lança, em 2009, a primeira versão ${ }^{9}$ do PMCMV, e em 2011 a segunda, chamada de PMCMV II. O PMCMV

[...] tem por finalidade
criar mecanismos de
incentivo à produção e
aquisição de novas
unidades habitacionais,
requalificação de imóveis
urbanos, produção ou
reforma de habitações
rurais [para famílias
divididas em faixas de
rendas de,
aproximadamente, até 10
salários mínimos].
(BRASIL, 2011, art. $1^{\circ}$ ).

A base de financiamento do PMCMV advém de recursos do Orçamento Fiscal (OGU), do Fundo de Arrendamento Residencial (FAR), do Fundo de Desenvolvimento Social (FDS), do Fundo Garantidor da Habitação Popular (FGHab), e também poderá receber recursos do FGTS.

O PMCMV possui um Comitê de Acompanhamento (CAPMCMV) com representantes do Ministério do Planejamento, da Fazenda e da Casa Civil para monitorar a 
evolução dos empreendimentos no país. Contudo, esse Comitê não possui participação popular e nem relação com o Conselho das Cidades, configurando-se como um instrumento meramente operativo, pois as decisões dos projetos são tomadas pelos promotores privados dos empreendimentos, isto é, as construtoras.

Considero necessárias algumas observações sobre as diretrizes do PMCMV. Entre elas: a) definição do público-alvo atrelado à renda e a definição do valor da renda familiar da faixa 1 (baixa renda) ser inferior a 3 salários mínimos, o que desconsidera as condições de pobreza dos trabalhadores e a redução de cobertura do programa para esta população; b) foco quantitativo da produção habitacional e desarticulação com as políticas urbanas, onde a legislação não expõe a forma de monitoramento dos municípios que produzirem empreendimentos que não contemplam infraestrutura e equipamentos sociais; c) produção de habitação social abarca apenas $11 \%$ da produção total do programa (ampliado para $47 \%$ até 2012), mesmo ante um déficit habitacional de $90 \%$ para a faixa de renda de até 3 salários mínimos; d) distanciamento ${ }^{10}$ do Programa em relação às diretrizes e princípios do Plano Nacional de Habitação, ao controle democrático e aos demais instrumentos de planejamento; e) base de financiamento se alicerça em recursos onerosos ${ }^{11}$, com baixa participação de fonte a fundo perdido e a ênfase na participação do mercado imobiliário na execução de financiamento habitacional com recursos do fundo público; f) compreensão do beneficiário do Programa como mutuário e implementação de fundo garantidor, para combater a inadimplência.

Em termos orçamentários, os recursos $^{12}$ investidos no programa somaram R\$ 16 bilhões e contrataram 2.072 milhões de moradias (2009 a 2012), destas $47 \%$ das unidades habitacionais (978 mil) foram para famílias da faixa 1 (baixa renda). Destaco a fragmentação e a imprecisão nas peças orçamentárias das informações sobre 0 PMCMV, pois não estão explicitas as fontes de recursos para financiar as mais de 2 milhões de moradias, o que indica que pelo volume de recursos necessários para tal, as fontes não são do orçamento público, implicando a continuidade do FGTS e da SBPE como pilar para o financiamento habitacional.

Recorrendo a pesquisas nas demais peças orçamentárias, os relatórios de gestão estimavam que entre os anos de 2009 a 2010, o PMCMV fez contratos envolvendo 1 milhão de moradias e com montante de $\mathrm{R} \$ 56$ bilhões, entre elas 483 mil foram destinadas à faixa 1 (baixa renda). Sendo esses financiados pela Caixa Econômica Federal e pelo Sistema Financeiro de Habitação (BRASIL, 2010, p. 15).

Já os relatórios posteriores a 2010 apontam que o PMCMV ampliaria a produção habitacional com meta de contratação de 2,4 milhões de moradias até 
2014. Para alterar a meta, houve algumas alterações no Programa, relacionadas aos parâmetros de financiamento para habitação popular e para concessão de subsídio, aumentando o teto do valor dos imóveis (de $\mathrm{R} \$$ 170 mil para $\mathrm{R} \$ 190$ mil), no valor de subsidio (de $\mathrm{R} \$ 23$ mil para $\mathrm{R} \$ 25$ mil) e na redução nas taxas de juros para a faixa 2, que foi para $5 \%$ e faixa 3 , que foi para $7,16 \%$ (BRASIL, 2012, p. 2).

Vale relembrar que um dos argumentos para criação do PMCMV era 0 enfrentamento ao déficit habitacional. Contudo, foi sob o PMCMV que o déficit aumentou em comparação aos anos anteriores, chegando a cerca de 6,490 milhões de moradia (FUNDAÇÃO JOÃO PINHEIRO, 2013). Se em 2008 o déficit habitacional era de 5,5 milhões, mesmo com a produção de 2 milhões de moradias, o déficit aumentou, isto é, ao invés de reduzir o déficit habitacional, o PMCMV fez o inverso.

Diversas análises sobre 0 PMCMV consideram como seus pontos críticos a periferização dos empreendimentos, a construção de grandes conjuntos padronizados; o incentivo ao programa de crédito ao produtor e ao consumidor com caráter de mercantilização da moradia, a ausência de relação com SNHIS, a desarticulação com a política urbana, a ausência de instrumentos de política fundiária e a desigualdade regional na distribuição dos recursos.
Entre tais pontos críticos, a ênfase na promoção da moradia centrada no mercado imobiliário caracteriza um processo de privilegiamento do produtor privado na política de habitação. Utilizando-se da estrutura administrativa e operacional adquirida do $\mathrm{BNH}$ pela $\mathrm{CEF}$, o mercado imobiliário conquistou as condições para viabilizar os projetos pleiteados. Para Bastos (2012), a Caixa Econômica, como agente operador do PMCMV, possibilita criar as condições necessárias para dinamizar o setor da construção civil. Por meio da liberação de crédito imobiliário para a produção, se adianta a realização do capital e se assume 0 financiamento de habitação social. Assim posto, 0 mercado imobiliário recebe fluxo permanente de fundo público e os libera para "[...] investimento privado nos fluxos de capital excedente." (BASTOS, 2012, p. 66). Nessa realidade, a classe trabalhadora fica submetida ao acesso mercantilizado da moradia.

\section{CONCLUSÃO}

0 modelo atual de desenvolvimento urbano segue bloqueando as cidades aos pobres, pois se alicerça num padrão de acesso à moradia com vista à propriedade privada da terra. Em detrimento ao direito à moradia e à função social da propriedade da terra, a especulação e a desorganização do espaço urbano seguem sendo a regra sob o domínio do capital (ROLNIK, 2008). 
No contexto de empreendedorismo urbano (HARVEY, 2005), as cidades passam a competir entre si com vista a atrair capital e investimentos, tendo os governos papel decisivo para minimizar os riscos ao capital e estimular a parcerias público-privadas. Estão em curso diversos projetos que adotam tal diretriz, como os projetos de revitalização de áreas centrais e portuárias, a implementação de grandes empreendimentos produtivos via parceria público-privada e concessões - Complexo Petroquímico do Rio de Janeiro (COMPERJ) (RJ) ${ }^{13}$, Belo Monte (PA) ${ }^{14}$ - e os megaeventos esportivos - Copa 2014 e Olimpíada 2016. Tais empreendimentos representam uma verdadeira sangria ao fundo público para atender os interesses do capital e o seu descompasso em garantir as necessidades básicas aos trabalhadores.

O prolongamento deste projeto nas cidades brasileiras se apresentou na reestruturação do mercado imobiliário, cujas marcas eram a centralização e a concentração de capitais a partir do Governo Lula. Nele foi mobilizado um conjunto de medidas que afirmava a entrada do mercado imobiliário no mercado financeiro, possibilitando captação de capitais e a diversificação construtiva e de segmento. Cardoso e Aragão (2011) destacam as ações do Estado na promoção da reestruturação do setor, como iniciativas de vantagens tributárias, segurança jurídico-legal e diversificação de financiamento público.
Tendo por base os princípios do social-liberalismo foram articuladas medidas de crescimento econômico e de incentivo à infraestrutura física e social como prioridades no governo de coalizão petista, particularmente após 2008, onde o mundo se deparava com uma crise econômica. A função do Estado diante da crise foi garantir as condições gerais de produção, reprimir as possíveis ameaças ao sistema e promover a legitimação junto aos trabalhadores. Nessas condições, foi reforçado um padrão de política habitacional alicerçada sobre o caráter pulverizado e mercantilizado da oferta, mesmo diante do agravamento das expressões da questão social provocado pela crise de acumulação e reprodução do capital.

\section{Compreendemos que a construção} de moradias para os segmentos mais pobres da população, ainda que não transforme sua condição social, Ihes possibilita uma melhoria de vida. Se no decorrer da constituição do PMCMV, os interesses do mercado imobiliário foram resguardados e estimulados, no marco da produção da cidade, a provisão habitacional não pode ser encarada como a produção das demais mercadorias. Produzir moradias é produzir espaço dentro de determinadas relações sociais. Conforme assinala Rolnik (2009, p. 5) "[...] casas empilhadas não fazem uma cidade, não constituem um tecido urbano." Isto é, tratar a habitação social como estratégia de alavancar os ganhos do mercado imobiliário, gera cidades descoladas das necessidades dos 
trabalhadores e acirra as contradições de classe.

\section{REFERÊNCIAS}

ANDRADE, E. S. J. A política habitacional no Brasil (1964-2011): do sonho da casa própria à minha casa, minha vida. Dissertação (Mestrado em Arquitetura e Urbanismo) - Programa de Pós-graduação em Arquitetura e Urbanismo, Escola de Arquitetura e Urbanismo, Universidade Federal Fluminense, Niterói, 2011.

AFONSO, J. R.; CASTRO, K. P. IPTU: o tributo esquecido. Revista Multi Cidades: Finanças dos Municípios do Brasil, Vitória, v. 9, p. 178181, dez. 2013. Disponível em: <http://www.aequus.com.br/anuarios/multicidad es_2013/>. Acesso em: 17 jan. 2014.

BASTOS, R. D. Economia política do imobiliário: o Programa Minha Casa Minha Vida e o preço da terra urbana no Brasil. Dissertação (Mestrado em Sociologia) Instituto de Filosofia e Ciências Humanas, Universidade Estadual de Campinas, Campinas, SP, 2012.

BEHRING, E. R. Rotação do capital e crise: fundamentos para compreender 0 fundo público e a política social. In: SALVADOR, E. et al. (Org.). Financeirização, fundo público e política social. São Paulo: Cortez, 2012. p.153-180.

et al. Política econômica e orçamento federal: uma análise da seguridade social brasileira entre 2008 e 2013. In: CONGRESSO BRASILEIRO DE ASSISTENTES SOCIAIS, 14., 2013, Águas de Lindóia. Anais... Águas de Lindóia: CFESS/CRESS, 2013.

BOTELHO, Adriano. 0 urbano em fragmento: a produção do espaço e da moradia pelas práticas do setor imobiliário. São Paulo: Annablume; Fapesp, 2007. Cap. 1 a 4.
BRASIL. Presidência da República. Controladoria-Geral da União. Balanço Geral da União: prestação de contas da Presidência da República, atuação por setor governamental - Ministério das Cidades. Brasília, DF: 2010.

Balanço Geral da

União: prestação de contas da Presidência da República, Siga Brasil, Execução de despesas LOA - Ministério das Cidades. Brasília, DF: 2012.

Decreto $\mathrm{n}^{0} 5.796$, de 6 de junho de 2006 . Regulamenta a Lei $n^{011.124, ~ d e ~}$ 16 de junho de 2005. Dispõe sobre a criação do Fundo Nacional de Habitação de Interesse Social e institui o Conselho Gestor do FNHIS. Diário Oficial da União, Brasília, DF, 2006.

. Lei n. 12.424, de 16 de junho de 2011. Altera a Lei no 11.977, de 7 de julho de 2009, que dispõe sobre o Programa Minha Casa, Minha Vida - PMCMV e a regularização fundiária de assentamentos localizados em áreas urbanas, as Leis nos 10.188, de 12 de fevereiro de 2001, 6.015, de 31 de dezembro de 1973, 6.766, de 19 de dezembro de 1979, 4.591, de 16 de dezembro de 1964, 8.212, de 24 de julho de 1991, e 10.406, de 10 de janeiro de 2002 - Código Civil; revoga dispositivos da Medida Provisória № 2.197-43, de 24 de agosto de 2001; e dá outras providências. Diário Oficial da União, Brasília, DF, 2011.

CARCANHOLO, M. Neoconservadorismo com roupagem alternativa: a Nova Cepal dentro do Consenso de Washington. In: CASTELO, R. (Org.). Encruzilhadas da America Latina no século XXI. Rio de Janeiro: Pão e Rosa, 2010. p.119-142.

CARDOSO, A. I.; ARAGÃO, T. A. A reestruturação do setor imobiliário e 0 Programa Minha Casa Minha Vida. In: MENDONÇA, J. G.; COSTA, H. S. M. Estado e Capital imobiliário: convergências atuais na produção do espaço urbano brasileiro. Belo Horizonte: Editora C/Arte, 2011. P. 81-104. 
Do fim do BNH ao Programa

Minha Casa Minha Vida: 25 anos da política habitacional no Brasil. In: CARDOSO, A. L. (org.). O Programa Minha Casa Minha Vida e seus efeitos territoriais. Rio de Janeiro: Letra Capital, 2013. p. 17-67.

COSTA, G. M. A contribuição da Teoria do espaço de Lefebvre para a análise urbana. In: LIMONAD, E. Entre a ordem próxima e a ordem distante: contribuições a partir do pensamento de Henri Lefebvre. Niteroi: UFF/GECEL, 2003. p. 9-15.

DEPARTAMENTO INTERSINDICAL DE ESTATÍSTICAS E ESTUDOS SOCIOECONÔMICOS. Estudo Setorial da Construção 2012. São Paulo, 2013. (Estudos e Pesquisas, n. 65).

FILGUEIRAS, L.; GONÇALVES, R. A economia política do Governo Lula. Rio de Janeiro: Contraponto, 2007.

FUNDAÇÃO JOÃO PINHEIRO. Déficit Habitacional Municipal no Brasil 2010. Belo Horizonte, 2013.

HARVEY, D. A produção capitalista do espaço. São Paulo: Annablume, 2005.

O Enigma do capital: e as crises do capitalismo. São Paulo: Boitempo, 2011.

IAMAMOTO, M. V. Serviço Social em tempo de capital fetiche: capital financeiro, trabalho e questão social. 2. ed. São Paulo: Cortez, 2008.

LEFEBVRE, H. A produção do espaço. Trad. Doralice Barros Pereira e Sérgio Martins. [S.I.: s. n.], 2006. Original: La production de l'espace. 4. ed. Paris: Anthropos, 2000.

MANDEL, Ernest. 0 capitalismo tardio. São Paulo: Abril Cultural, 1982. (Os Economistas).

MARICATO, E. Brasil, cidades: alternativas para a crise urbana. Petrópolis, RJ: Vozes, 2001.
MOTA, A. E.; AMARAL, A.; PERUZZO, J. 0 novo-desenvolvimentismo e as políticas sociais na America Latina. In: MOTA, A. E. Desenvolvimento e construção de hegemonia: crescimento econômico e reprodução da desigualdade. São Paulo: Cortez, 2012. p.153-178.

PAULO NETTO, J. Capitalismo Monopolista e Serviço Social. 7. ed. São Paulo: Editora Cortez, 2009.

ROLNIK, R. A lógica da desordem. Jornal Le Monde Diplomatique Brasil, Rio de Janeiro, ago. 2008.

. Casas empilhadas não fazem uma cidade. Jornal dos Engenheiros, Rio de Janeiro, ano XIV, n. 132, p. 4-5, maio 2009. Entrevista a Julia Gaspar.

El derecho a una vivienda adecuada: nota del Secretario General. Asamblea General, Naciones Unidas, A/67/286, 10 ago. 2012.

SALVADOR, E.; TEIXEIRA, S. Implicações da crise no financiamento e no controle democrático das políticas sociais. In: ENCONTRO NACIONAL DE PESQUISADORES EM SERVIÇO SOCIAL, 13., 2012, Juiz de Fora. Anais... Juiz de Fora: ABEPSS, 2012.

Orçamento e políticas sociais: metodologia de análise na perspectiva crítica. Revista de Políticas Sociais, São Luís, v. 18, n.1, p. 15-32, jan./jun. 2014.

SHIMBO, Lucia Zanin. Empresa construtora, capital financeiro e a construção de habitação social de mercado. In: MENDONÇA, J. G.; COSTA, H. S. M. Estado e capital imobiliário: convergências atuais na produção do espaço urbano brasileiro. Belo Horizonte: Editora C/Arte, 2011.

NOTAS: 
1 Partindo das contribuições de Lefebvre (2006), entendemos produção do espaço como produto social das relações sociais no modo de produção capitalista, que produz e organiza o espaço (e o tempo) sob relações sociais determinadas historicamente.

2 O conceito de social-liberalismo envolve o processo político e econômico do capital na perspectiva de adaptação as reformas, particularmente dos países periféricos, gerenciando as consequências da abertura comercial e financeira através de programas que fomente a equidade social (CARCANHOLO, 2010) e se distingue do temo novo-desenvolvimentismo por esse possuir forte carga ideológica. A crítica ao socialliberalismo encontra-se em Filgueiras e Gonçalves (2007) que qualifica o padrão de desenvolvimento capitalista desde os anos 1990 como modelo liberal periférico.

3 Está em andamento a campanha Moradia Digna: Uma Prioridade Nacional, promovida por entidades patronais e de movimentos sociais urbanos. A campanha busca a aprovação da PEC 285-A/2008 que garante o percentual de $2 \%$ do orçamento da União e $1 \%$ dos estados e dos municípios a serem alocados no FNHIS para desenvolvimento de ações com vista a reduzir o déficit habitacional no país.

4 Os Programas Finalísticos são definidos no PPA como aqueles em que: "[...] a) sua implementação são ofertados bens e serviços diretamente à sociedade e são gerados resultados passíveis de aferição por indicadores." (BRASIL, 2007, p. 50).

${ }^{5}$ Em que pese as críticas sobre a criação de sistemas para a organização de algumas políticas sociais, principalmente, as que envolve a falta de critérios que contemplem a diversidade regional, a diminuição de autonomia dos entres federados em relação aos indicadores e regras de adesão e centralização das decisões sobre o sistema a União. Considero um avanço em termos institucionais a constituição desses sistemas na perspectiva de reduzir, mesmo que ainda periférica, a fragmentação e o paralelismo de ações em determinadas políticas, além de instituir instrumentos para a organização da política social como planos, padrão de financiamento, órgão gestor e conselho.

6 Cabe lembrar que a moradia foi reconhecida como direito social e incluída no artigo $6^{\circ}$ da Constituição Federal por meio da Emenda Constitucional $n^{0} 26$, de 14 de fevereiro de 2000.

7 Salvador e Teixeira (2014) diferenciam três formas de organização dos fundos especiais que são o fundo de gestão democrática, o fundo de gestão especial (ao qual os autores enquadram o FNHIS) e o fundo de natureza contábil (ao qual a legislação enquadra 0 FNHIS).
8 Em termos orçamentários, função refere-se a área de alocação de recursos de um governo, como saúde, saneamento, habitação, entre outras.

9 Segundo Cardoso (2013, p. 43), o que difere as duas versões é que no PMCMV 2 há "[...] melhoria do padrão construtivo das unidades habitacionais, que permite 0 uso misto (residencial e comercial) e 0 estímulo a utilização de soluções energéticas sustentáveis."

10 O que se sabe, é que há uma priorização do Governo de instituir o PMCMV como agente da produção de habitação, ficando o FNHIS com a responsabilidade nas intervenções urbanas, isto é, numa posição subsidiária tanto financeira quanto interventiva sobre a política habitacional.

${ }^{11}$ Consideram-se recursos onerosos aqueles que exigem retorno (pagamento) e estão vinculados a operações de crédito ou financiamentos, exemplo os recursos do FGTS.

12 Não consta o montante de recursos alocados pelo FGTS e do SPBE por não estarem descritos no orçamento público. Para essa pesquisa, nos restringimos apenas aos recursos financiados com fontes da OGU, FAR, FDS. O quantitativo de unidades habitacionais contratadas é absoluto, não sendo discriminadas as contratadas com recursos do orçamento público.

13 O COMPERJ está sendo construído no município de Itaboraí, no estado do Rio de Janeiro, concebido como polo de abastecimento de petróleo. Está entre as obras de maior relevância do Programa de Aceleração do Crescimento (PAC).

14 A Usina Hidrelétrica de Belo Monte está sendo construída no Rio Xingu no estado do Pará. Objeto de parceria público-privada, fundo de pensão e investimentos de empresas autoprodutoras movimentará R\$ 63 bilhões. Bem como o COMPERJ, Belo Monte está entre as obras de maior relevância do PAC.

\author{
Aline Cavalcanti de Abreu \\ Assistente Social \\ Bolsista da CAPES \\ Doutoranda em Serviço Social pelo Programa de Pós- \\ Graduação em Serviço Social (PPGSS) da Universidade \\ do Estado do Rio de Janeiro (UERJ) \\ E-mail: alineabreu1@yahoo.com.br
}

\section{Universidade do Estado do Rio de Janeiro - UERJ}

Rua São Francisco Xavier, 524 - Bloco A - Sala 1006 Maracanã, Rio de Janeiro - RJ CEP: $20550-900$ 